\title{
The role of friction in orthodontics
}

Mariana Ribeiro Pacheco', Wellington Corrêa Jansen², Dauro Douglas Oliveira ${ }^{3}$

Introduction: Sliding mechanics is widely used during orthodontic treatment. One of the disadvantages of this mechanics is the friction generated at the bracket/archwire interface, which may reduce the amount of desired orthodontic movement obtained. Due to the application and great acceptance of this type of mechanics, the role of friction in Orthodontics has been of interest for both clinicians and scientists.

Objective: Therefore, this article discussed how friction affects orthodontic tooth movement, with an approach to its clinical implications as well as the evolution of dental materials and its properties regarding resistance to sliding.

Keywords: Orthodontics. Orthodontic brackets. Dental materials.

${ }^{1}$ MSc in Orthodontics, PUC-Minas, Brazil.

${ }^{2}$ Associate Professor, PUC-Minas, Brazil.

${ }^{3}$ Head of the Masters Program in Orthodontics, PUC-Minas, Brazil.

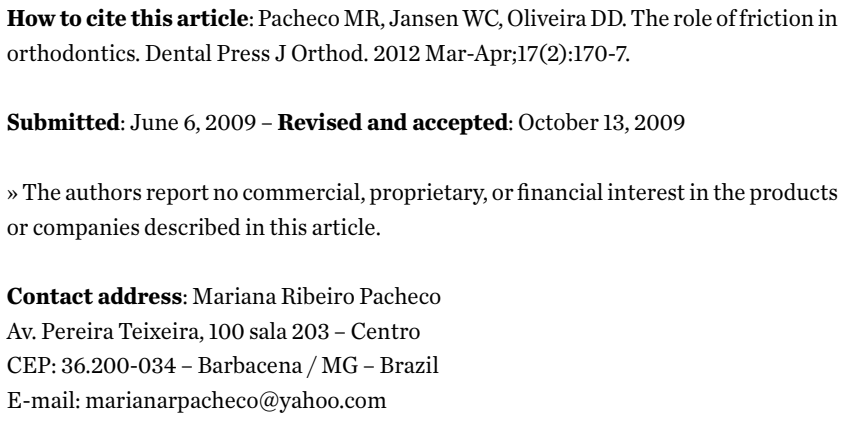

Submitted: June 6, 2009 - Revised and accepted: October 13, 2009

" The authors report no commercial, proprietary, or financial interest in the products or companies described in this article.

Contact address: Mariana Ribeiro Pacheco Av. Pereira Teixeira, 100 sala 203 - Centro CEP: 36.200-034 - Barbacena / MG - Brazil E-mail: marianarpacheco@yahoo.com 


\section{INTRODUCTION}

The friction present during orthodontic sliding mechanics represents a clinical challenge to the orthodontists because high levels of friction may reduce the effectiveness of the mechanics, decrease tooth movement efficiency and further complicate anchorage control. ${ }^{1}$ One of the primary focuses of the search for ideal conditions for orthodontic tooth movement (OTM) is the reduction of friction at the bracket-wire-ligature interface in certain stages of treatment ${ }^{2}$. Therefore, lower but still sufficient to promote OTM forces could be used. ${ }^{3}$

Orthodontics, as part of modern sciences, is also influenced by the rapid and constant technological development observed in today's society, most particularly, in regards to dental materials. According to Kusy, ${ }^{4}$ an important researcher on this topic, the knowledge about biomechanics and orthodontic materials complement each other. Therefore, a good comprehension about biomechanical concepts is very important for the development of innovative orthodontic materials and such innovations may result in new biomechanical principles.

In this context, one of the major goals of the orthodontic manufacturing companies is the search for new products that would generate less friction during sliding mechanics. Over the last two decades, major efforts have been made to develop the so called low-friction brackets, wires and ligatures. In order to carefully determine the real cost-benefit of these products, the orthodontist must critically understand the role of friction during sliding mechanics. Therefore, the objectives of this article are to: (1) Discuss the clinical implication of friction on OTM; (2) debate which variables and how some orthodontic materials may affect friction during sliding mechanics and, finally; (3) consider the real clinical application of the new low-friction brackets, wires and ligatures.

\section{FRICTION AND SLIDING MECHANICS}

Orthodontic tooth movement during space closure may be performed with two different types of mechanics. The first is the "Segmented Arch Mechanics" (SAM), which consists in bending loops on stainless steel (SS) or titanium molybdenum (TMA) wires. When SAM is implemented, the tooth or group of teeth move due to the force to moment ratio generated during the activation of the loops. SAM is also called "frictionless mechanics" because the brackets and tubes do not slide along the archwire $^{5}$. The other space closure mechanics used in Orthodontics is the Sliding Mechanics (SM), which involves the actual sliding of brackets and tubes along the wire. ${ }^{6}$

Although SAM provides excellent control of tooth inclination during space closure, it is not as popular as SM. The possible SAM disadvantages are the need for a refined biomechanics understanding to properly activate the springs and closing loop archwires, as well as the increased chances to cause patient discomfort when these loops are not adequately adjusted. ${ }^{6}$ Conversely, the probable SM advantages are the simpler archwires used, the shorter chair time and lower chances to cause patient discomfort ${ }^{7}$. However, SM also presents disadvantages such as the higher chances to generate dental tipping and the friction generated at the bracket-wire-ligature interface. ${ }^{8}$

Friction is the force that resists against the movement of one surface in relation to another and that acts on the opposite direction of the desired movement ${ }^{1}$. When two surfaces slide one over the other, two force components are created: Frictional Force (FF), tangent to the Contacting Surface (CS) and Normal Force (N), perpendicular to the FF and to the $\mathrm{CS}^{8}$ (Fig 1). FF is directly proportional to $\mathrm{N}$ and dependent on the friction coefficient of both contacting surfaces. This coefficient is a constant closely related to the superficial characteristics of each material involved. ${ }^{1,8}$

There are two types of FF: Static Friction (SF) and Kinetic Friction (KF) ${ }^{9}$. SF is the smallest force needed to initiate a movement between two solid bodies that were static in relation to each other. Kinetic friction is the force that resists against the sliding movement of a solid object against another at a constant speed. SF is always greater than $\mathrm{KF}$ since it is harder to change a body from its inertial situation than to maintain it moving. ${ }^{1,8}$ When an orthodontist tries to slide a tooth along the archwire, the tooth is subjected to an alternate movement of tipping and uprighting, thus moving in a sequential number of small and consecutive movements. 


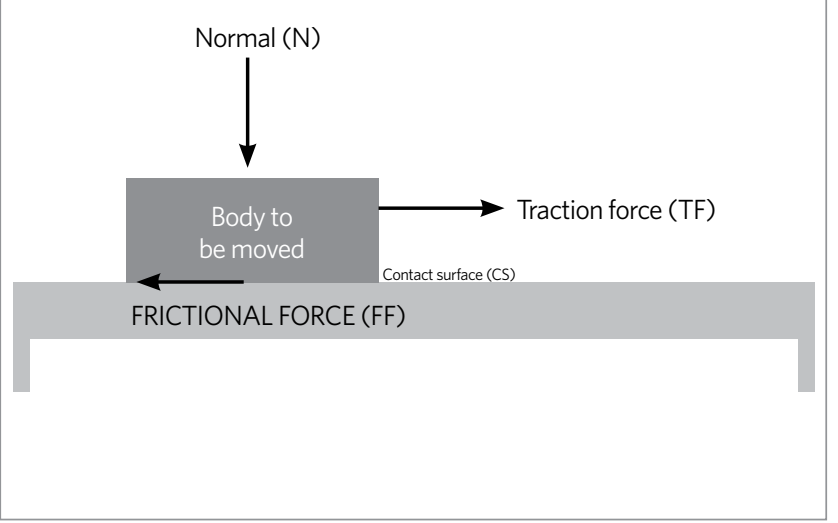

Figure 1 - Different forces acting over a body under traction on top of a surface. Body to be moved, contact surface (CS), Traction force (TF), Friction force (FF).

Therefore, SF is more important than KF during space closure. $^{8}$

The application of the retraction force during space closure with SM generates a moment on the tooth's crown that causes an initial crown tipping and later root uprighting. This moment is determined by the location of the point of force application in relation to the center of resistance of the tooth or group of teeth. A number of successive crown tippings and root uprightings take place in the same plane of space towards the direction of the applied force. When the tooth inclines, the orthodontic wire binds against the edge of the bracket slot ("binding effect"), increasing friction and further restricting OTM. Greater frictional forces mean that an increased number of tipping and uprighting must take place. Thus, friction should be minimized to achieve a more efficient sliding movement of the tooth along the arch wire. ${ }^{8}$

When the orthodontic wire slides through the bracket slot and the tubes, some resistance to sliding always takes place at the bracket/wire interface. This phenomenon is observed during leveling and alignment, space closure and even during torque expression at the end of treatment. ${ }^{10} \mathrm{~A}$ percentage of the orthodontic force applied to the teeth is lost as static friction and the rest is transferred to the tooth and its periodontium, generating the actual OTM. Kojima e Fukui ${ }^{11}$ evaluated the influence of friction on OTM using the finite element method and reported that approximately $60 \%$ of the orthodontic force applied to a tooth is lost as SF. Thus, the biological tissue response to the mechanical stimulus takes place only if the force is strong enough to overcome SF. Therefore, higher levels of friction during sliding mechanics require the application of higher orthodontic forces and may compromise the amount of OTM obtained as well as complicate anchorage control. ${ }^{5-8}$

Despite the undesirable effects that friction may cause in some stages of the orthodontic treatment, there are other clinical situations in which the presence of friction is beneficial such as when the orthodontist wants to use a group of teeth as a larger anchorage unit or during torquing at the finishing stage of treatment., ${ }^{1,2}$ Therefore, a good understanding of how friction may impact the clinical development of the orthodontic therapy, the variables that increase friction and how they can be better controlled is very important to the orthodontist who wishes to improve his or her clinical skill and consistently provide better services to the patients.

\section{VARIABLES THAT MAY INFLUENCE FRICTION DURING OTM}

The variables affecting the role of friction during orthodontic treatment could be divided in two large groups: Biological and mechanical. The major biological factor influencing SF seems to be the presence of saliva, which acts as a lubricant and plays an important role in friction reduction. ${ }^{12}$ This information may be important when treating patients presenting xerostomia or those who regularly take medications that reduce the production of saliva. The influence of saliva in friction reduction may also be relevant when an orthodontist consider the clinical application of in vitro laboratory studies. Some of these experiments do not simulate the presence of saliva and neither point out this methodological limitation.

The accumulation of debris on the surface of orthodontic wires also appears to be a significant variable that may increase friction throughout the orthodontic treatment. Significant deposits of biofilm were registered on orthodontic archwires after only 8 weeks of intraoral use. ${ }^{13}$ The number of adult patients seeking orthodontic care has been 
increasing in the past decades and these patients have higher tendencies for calculus formation. Therefore, the orthodontist who constantly treats adult individuals should pay attention to the presence of debris on the archwires that may be used for several months. Stainless steel archwire cleaning following clinical use with ultrasound for 15 seconds or with steel wool sponge for one minute were efficient methods to decrease the static friction of used archwires. ${ }^{14}$

The third biological variable that may be clinically relevant is the biodegradation that the orthodontic materials suffer throughout the orthodontic treatment. A recent evaluation of some important properties of brackets and elastic ligatures after their use brought some light to some of the questions related to the biodegradation of orthodontic materials. ${ }^{15,16}$ The examination of metallic brackets post-orthodontic treatment revealed alterations such as corrosion, structural fatigue and plastic deformation. Different levels of biofilm were registered at the surface of these products and carbon, oxygen, calcium and phosphorus were found superficially. Commercially available brackets of two different manufacturers presented up to $20 \%$ more friction than their out of the box correspondents. ${ }^{15}$ Differently than the brackets, elastic ligatures showed similar levels of friction both brand new or after different times of intraoral use. ${ }^{16}$

The physical and mechanical properties of orthodontic brackets deserve special attention when the effects of friction on OTM are considered. In this context, the type of material used to construct the bracket is the first property to be evaluated. Metal brackets present lower friction coefficients than ceramic and plastic brackets and they are considered the golden standard to perform sliding mechanics. ${ }^{17}$ Plastic brackets showed lower values of friction than polycrystalline ceramic brackets. ${ }^{17}$ Others studies investigated possible static friction differences between poly and monocrystalline ceramic brackets and no significant differences were registered..$^{12,18}$ Omana et $\mathrm{al}^{9}$ reported that scanning electronic microscopy evaluations showed no major surface roughness differences between the two types of ceramic brackets and this property could not be pointed out as the cause for different levels of friction between mono and polycrystalline ceramic brackets. The first group presented a slightly smother slot surface, but the levels of friction were very similar between the two groups. ${ }^{9}$

The insertion of a metal slot in ceramic brackets has showed relatively good success to reduce the levels of SF on this type of esthetic orthodontic brackets. This structural modification aimed to combine the esthetic of a ceramic bracket to the clinical performance of metal brackets ${ }^{4}$. Ceramic brackets with metal slots did show lower levels of SF than pure ceramic brackets. However, their levels of SF remained higher than those registered with metal brackets. ${ }^{19}$ This difference may be due to the different ceramic and metal expansion coefficients, ${ }^{4}$ or to the presence of a gap between the ceramic bracket body and the metal $\operatorname{slot}^{20}$ what could be responsible for an inaccurate adaptation between these two major components, compromising its clinical performance.

Bracket size, slot depth and width also influence the amount of friction registered during sliding mechanics. Wider brackets present higher frictional forces than brackets with reduced width due to the greater area of surface contact between the bracket and the wire. In addition, a greater angulation of the wire in relation the bracket slot is also related to an increased resistance to sliding. ${ }^{21}$

The type of orthodontic wire used will also influence the amount of friction during the different stages of treatment and the wire alloy, its cross section and diameter as well as the surface roughness should be taken into consideration. Cacciafesta et $\mathrm{al}^{22}$ evaluated the amount of friction related to the most commonly alloys used in orthodontic archwire manufacture: Stainless steel (SS), nickel-titanium (NiTi) and TMA. 0.016-in, 0.017 x 0.025-in and $0.019 \times 0.025$-in wires were tested and the results showed that SF increases when thicker wires of the same alloy were tested. TMA wires presented higher frictional resistance than SS and NiTi wires of same diameter. According to Omana et al, ${ }^{9}$ the influence of the wire size on friction increases because thicker wires fulfill the bracket slot and the amount of force needed to cause orthodontic tooth movement is also increased. Saunders and $\mathrm{Kusy}^{18}$ also reported higher frictional values with 
TMA wires, followed by the NiTi arches. They suggested that the increased TMA surface roughness and the greater elasticity of the titanium alloys as the reasons for such findings.

Another mechanical variable that plays an important role in friction formation at the bracket/ wire interface, constantly present in daily clinical orthodontics is the method of wire ligation to the bracket. Steel or elastic ligatures may contribute differently to friction increase depending on how they are used. ${ }^{23}$ Steel ligatures influence resistance to sliding according to the intensity of the ligation. They can generate higher amounts of SF than elastic ligatures if they are tightly used. However, if they are loosely inserted, small gaps between the wire and the bracket slot remain present and smaller SF values may be registered ${ }^{24}$. The amount of SF may also vary depending on the type of elastic ligature used to ligate the archwire to the brackets. Hain et $\mathrm{al}^{24}$ reported that elastic ligatures with decreased surface roughness generated lower amounts of friction.

Elastic ligatures tied as the number 8 generated increased levels of SF with all ligatures tested.

The high number of variables that may influence friction complicates the determination of the exact variables acting in all different clinical scenarios especially when all possible types of bracket/archwire/ligature combinations are considered. The search for new materials that decrease the amount of friction continues and it has actually increased in recent years, as discussed below.

\section{RECENTLY INTRODUCED ORTHODONTIC MATERIALS TO REDUCE FRICTION}

The golden standard materials to perform sliding mechanics is the combination of stainless steel brackets and wires ${ }^{1,4}$. The main technological innovations that have been tried to create low-friction orthodontic materials could be divided in design innovations and surface treatments. Among the various attempts to change the bracket design to reduce friction, the use of self-ligating brackets (SLB) has been the most tested.

During the past decade, SLB have been advertised as the new great innovation in Orthodontics. However, like some other "innovations", the idea of having a self-ligating bracket is actually not that new. The first report of a SLB was the Russell Lock appliance in $1935 .{ }^{1-4}$ Other brackets with similar concepts have been introduced in the market and a few of these SLB have been consistently available since the early 80 's ${ }^{25}$. SLB present a clip incorporated to its buccal surface that locks the wire within the slot and transforms the bracket in a tube-like device, thus eliminating the need for elastic or steel ligatures. ${ }^{2,3}$ Passive SLB present a clip that does not press the arch wire against the internal walls of the bracket slot (Fig 2A). Conversely, active or interactive SLB present a spring clip that pushes wires of greater diameter against the bracket slot (Fig 2B).

There were no significant differences between the amounts of friction registered when passive and active SLB where tested with round wires, However, when heavier rectangular wires were implemented active SLB showed more resistance to sliding than passive SLB. ${ }^{26}$ Ehsani et al ${ }^{27}$ performed a systematic review of the literature on SLB and reported that based on the evaluation of the papers published until august 2008, there were no evidence to support that SLB brackets generated significantly less friction than conventional brackets in the following clinical situations: (1) when rectangular stainless steel wires were used; (2) with marked dental tipping or torquing and (3) when treating complex malocclusions. The fracture of the buccal clip, the difficulty in using elastic chains and the cost up to ten times higher than conventional brackets of the same manufacturer have been reported as other limitations of SLB. ${ }^{2,4}$ However, the authors of this manuscript acknowledge that the orthodontic companies have been heavily investing in SLB both on research and in advertisement. Therefore, as further laboratory and clinical studies take place, improvements may decrease the current SLB limitations, reduce their cost and if all advantages suggested by the manufacturers are confirmed, the use of SLB as the golden standard for orthodontic brackets may became truly evidenced based.

A polyurethane elastic ligature presenting a very creative design (Slide ${ }^{\star}$ Leone Ortodonzia e Implantologia, Florence, Italy) is another "new" 

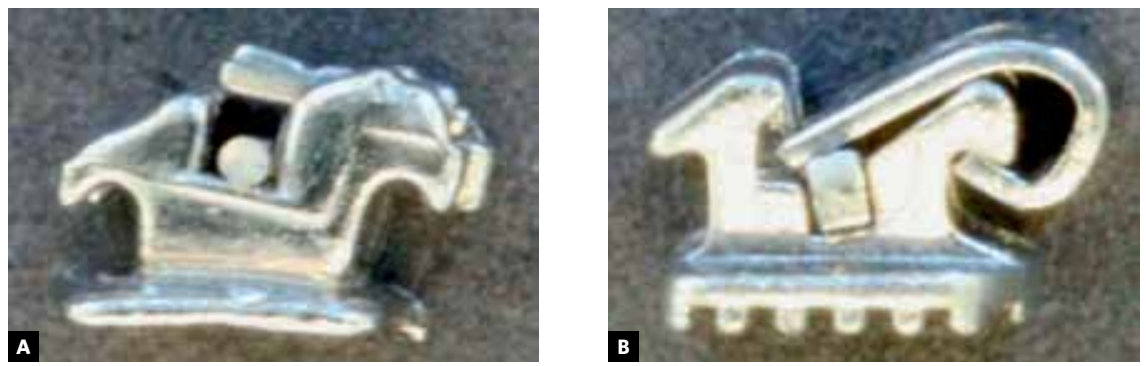

Figure 2 - A) Passive SLB: The buccal clip does not touch the arch wire, B) Active SLB: The buccal clip may press the wire against the internal surfaces of the slot depending on the wire cross section and diameter.

low-friction material recently introduced in the market. This ligature combined to a conventional bracket forms a tube-like structure (Fig 3). Baccetti e Franchi ${ }^{28}$ reported significant lower resistance to sliding with the Slide ligature than with conventional elastic ligatures. They concluded that this newly-designed elastic ligature may be used to generate a low-friction system when conventional brackets were used. Another possible advantage of this system would be the possibility to selectively use this ligature in one tooth or in some teeth were lower levels of friction were desired.

Finally, the efforts to discover technological innovations to decrease friction in Orthodontics are not limited to design modifications. The use of different superficial treatment of orthodontic materials has also been explored. A new type of elastic ligature that incorporated a technology named Metafasix $^{\circledast}$ (Super Slick Elastic Modules ${ }^{\oplus}$, TP Orthodontics, La Porte, IN, USA) was recently introduced. According to the manufacturer, the engineering process is similar to the one implemented to fabricate stents used to treat coronary heart disease, consisting of a water resistance polymeric coating, thus making the elastic ligature extremely slippery in the presence of saliva. Hain et $\mathrm{al}^{24}$ reported approximately $60 \%$ of friction reduction when these elastic ligatures were used.

Diamond-like carbon (DLC) surface coating of SS and NiTi orthodontic wires have been suggested to decrease static frictional force. ${ }^{29}$ These ions were incorporated to the surface of wire during the manufacturing process, increasing the wire hardness and significantly reducing SF when compared to the conventional orthodontic wires. The same technology was recently tested to improve the clinical performance of stainless steel brackets. The initial in vitro results were very promising for both increasing the superficial hardness and reducing the resistance to sliding. ${ }^{30}$

\section{CONCLUSION}

1. The resistance to sliding in Orthodontics is multifactorial. It is directly influenced by the types of materials used and affects orthodontic tooth movement efficiency. The presence of friction is unfavorable in many clinical situations. However, it may be very important in others.

2. The biological variables influencing friction seem to have been overlooked by orthodontists. Simple factors such as the accumulation of debris over the wire surface and the brackets' biodegradation registered after intraoral use may be as important as the type of material used when friction in Orthodontics is considered.

3. The physical or mechanical variables that influence friction formation during OTM are more frequently researched than the biological variables. They should be carefully taken into consideration during the different stages 

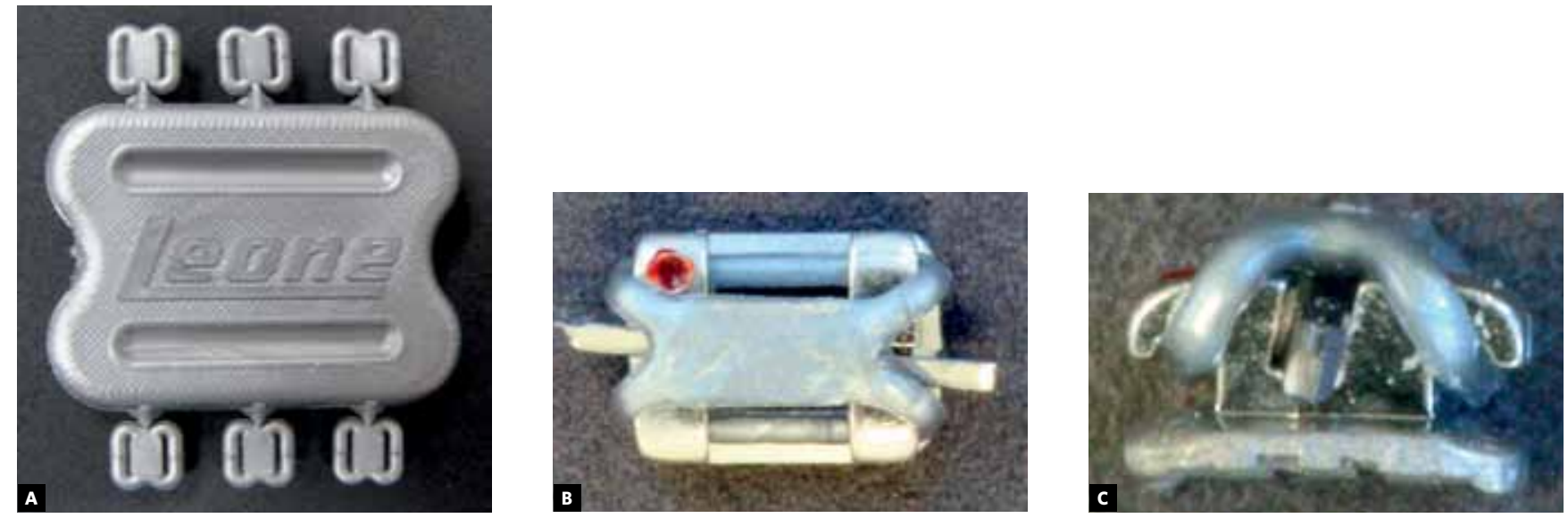

Figure 3 - A) Slide ${ }^{\circledR}$ elastic ligature, B) Frontal view of the ligature tied to a conventional metal bracket, C) Lateral view of this low-friction system, where there is no pressure on the orthodontic wire.

of the orthodontic treatment to increase efficiency in different clinical situations.

4. The technological innovations used to develop new low-friction materials such as the design alterations and the surface treatments seem to present good potential to reduce friction in specific clinical situations. However, the cost of these materials is still significantly higher than the traditionally used materials and their real cost to benefit remains scientifically questionable.

5. The need to increment orthodontic materials research especially performing studies with greater direct clinical application is undisputed. These studies would help clini- cal orthodontists to better understand the performance of all materials available and to critically follow the new products introduced in the market. Therefore, the orthodontist would be able to identify which of these new materials may actually contribute to diminish the clinical limitations of some orthodontic materials.

\section{ACKNOWLEDGEMENTS}

The authors would like to thank Dr. Telma Martins de Araújo (Head Professor of Orthodontics, Federal University of Bahia) for the invitation to write this manuscript. 


\section{REFERENCES}

1. Rossouw EP. Friction: an overview. Semin Orthod. 2003:9(4):218-22.

2. Pizzoni L, Ravnholt G, Melsen B. Frictional forces related to self-ligating brackets. Eur J Orthod. 1998;20(3):283-91.

3. Rossouw EP, Kamelchuk LS, Kusy RP. A fundamental review of variables associated with low velocity frictional dynamics. Semin Orthod. 2003;9(4):223-35.

4. Kusy RP. Ongoing innovations in biomechanics and materials for the new millennium. Angle Orthod. 2000;70(5):366-76.

5. Shroff B, Lindauer SJ, Burstone CJ, Leiss JB. Segmented approach to simultaneous intrusion and space closure: biomechanics of the three-piece base arch appliance. Am J Orthod Dentofacial Orthop. 1995;107(2):136-43.

6. Staggers J, Germane N. Clinical considerations in the use of retraction mechanics. J Clin Orthod. 1991;25(6):364-9.

7. Ziegler $P$, Ingervall $B$. A clinical study of maxillary canine retraction with a retraction spring and with sliding mechanics. Am J Orthod Dentofacial Orthop. 1989;95(2):99-106

8. Nanda RS, Ghosh J. Biomechanical considerations in sliding mechanics. In: Nanda R. Biomechanics in clinical orthodontics. Philadelphia: WB Saunders Company; 1997. p. $188-217$

9. Omana HM, Moore RN, Bagby MD. Frictional properties of metal and ceramic brackets. J Clin Orthod. 1992;26(7):425-32.

10. Downing A, McCabe JF, Gordon PH. A study of frictional forces between orthodontic brackets and archwires. Br J Orthod. 1994;21(4):349-57.

11. Kojima Y, Fukui H. Numerical simulation of canine retraction by sliding mechanics. Am J Orthod Dentofacial Orthop. 2005;127(5):542-51.

12. Kusy RP, Whitley J. Influence of fluid media on the frictional coefficients in orthodontics sliding. Semin Orthod. 2003;9(4):281-9.

13. Marques IS, Araújo AM, Gurgel JA, Normando D. Debris, roughness and friction of stainless steel archwires following clinical use. Angle Orthod. 2010;80(3):521-7.

14. Normando D, Araújo AM, Marques ID, Dias CGBT, Miguel JA. Archwire cleaning after intraoral ageing: the effects on debris, roughness, and friction. Eur J Orthod. 2011 Oct 19. [Epub ahead of print]

15. Regis S Jr, Soares P, Camargo ES, Guariza Filho O, Tanaka O, Maruo H. Biodegradation of orthodontic metallic brackets and associated implications for friction. Am J Orthod Dentofacial Orthop. 2011;140(4):501-9.

16. Crawford NL, McCarthy C, Murphy TC, Benson PE. Physical properties of conventional and Super Slick elastomeric ligatures after intraoral use. Angle Orthod. 2010;80(1):175-81.

17. Bazakidou E, Nanda RS, Duncanson MG Jr, Sinha P. Evaluation of frictional resistance in esthetic brackets. Am J Orthod Dentofacial Orthop. 1997;112(2):138-44.
18. Saunders C, Kusy RP. Surface topography and frictional characteristics of ceramic brackets. Am J Orthod Dentofacial Orthop. 1994;106(1):76-87.

19. Braga CP, Vanzin GD, Marchioro EM, Beck JCP. Avaliação do coeficiente de atrito em bráquetes metálicos e estéticos com fios de aço inoxidável e beta-titânio. Rev Dental Press Ortod Ortop Facial. 2004;9(6):70-83.

20. Nishio C, Motta AFJ, Elias CN, Mucha JN. In vitro evaluation of frictional forces between archwires and ceramic brackets. Am J Orthod Dentofacial Orthop. 2004;125(1):56-64.

21. Frank CA, Nikolai RJ. A comparative study of frictional resistances between orthodontic bracket and arch wire. Am J Orthod. 1980;78(6):593-609.

22. Cacciafesta V, Sfondrini MF, Scribante A, Klersy C, Auricchio F. Evaluation of friction of stainless steel and esthetic self-ligating brackets in various bracketarchwire combinations. Am J Orthod Dentofacial Orthop. 2003;124(4):395-402.

23. Kahlon S, Rinchuse D, Robison JM, Close JM. In-vitro evaluation of frictional resistance with 5 ligation methods and Gianelly-type working wires. Am J Orthod Dentofacial Orthop. 2010;138(1):67-71

24. Hain M, Dhopatkar A, Rock P. The effect of ligation method on friction in sliding mechanics. Am J Orthod Dentofacial Orthop. 2003;123(4):416-22.

25. Berger J. The Speed appliance: a 14-year update on this unique self-ligating orthodontic mechanism. Am J Orthod Dentofacial Orthop. 1994;105(3):217-23.

26. Pacheco MR, Oliveira DD, Smith-Neto $P$, Jansen WC. Evaluation of friction in selfligating brackets subjected to sliding mechanics: an in vitro study. Dental Press J Orthod. 2011;16(1):107-15.

27. Ehsani S, Mandich MA, El-Bialy TH, Flores-Mir C. Frictional resistance in selfligating orthodontic brackets and conventionally ligated brackets. A systematic review. Angle Orthod. 2009;79(3):592-601.

28. Baccetti T, Franchi L. Friction produced by types of elastomeric ligatures in treatment mechanics with the preadjusted appliance. Angle Orthod. 2006:76(2):211-6

29. Muguruma T, lijima M, Brantley WA, Mizoguchi I. Effects of a diamond-like carbon coating on the frictional properties of orthodontic wires. Angle Orthod. 2011;81(1):141-8.

30. Muguruma T, lijima M, Brantley WA, Nakagaki S, Endo K, Mizoguchi I. Frictional and mechanical properties of diamond-like carbon-coated orthodontic brackets. Eur J Orthod. 2011 Sept 20. [Epub ahead of print] 